\title{
Autonomia: uma abordagem interdisciplinar
}

\section{Autonomy: an interdisciplinary approcah}

\author{
Luiza Vieira Sá1, Reinaldo Ayer de Oliveira²
}

Sá LV. Oliveira RA de. Autonomia: uma abordagem interdisciplinar. Saúde, Ética \& Justiça. 2007;12(1/2):5-14.

RESUMO: A partir do pressuposto de que ser humano não nasce autônomo, mas torna-se autônomo, através de um processo de desenvolvimento bio-psico-social, surge a necessidade de se analisar a autonomia sob o enfoque das ciências sociais, de modo a congregar conceitos e possibilitar a compreensão do todo. Esse texto pretende demonstrar que no seu processo de desenvolvimento biológico, psicológico e social, o ser humano é influenciado por diversas variáveis, que irão, de certa forma, determinar o "grau" de autonomia que ele possui. Essas variáveis não contaminam a sua autonomia, ao contrário, fazem parte dela. Mas, existem outros fatores sócio-econômicos e culturais que influenciam o processo de escolha e tomada de decisão. Estes fatores sim reduzem a autonomia do indivíduo.

DESCRITORES: Autonomia. Bioética. Desenvolvimento.

1 Graduada em Direito pela Universidade Federal do Mato Grosso do Sul. Pós-Graduanda em Ciências Sociais da Universidade de São Paulo. Aluna da Disciplina de Bioética e Direito da Faculdade de Direito da Universidade de São Paulo.

2 Docente do Departamento de Medicina Legal, Ética Médica, Medicina Social e do Trabalho da Faculdade de Medicina da Universidade de São Paulo. Coordenador Adjunto da Disciplina de Bioética e Direito da Faculdade de Direito da Universidade de São Paulo.

Endereço para correspondência: Reinaldo Ayer de Oliveira. Faculdade de Medicina da Universidade de São Paulo. Departamento de Medicina Legal, Ética Médica e Medicina Social e do Trabalho. Rua Teodoro Sampaio, 115. CEP 05405-000. São Paulo, SP. e-mail: rayer@usp.br 
Sá LV. Oliveira RA de. Autonomia: uma abordagem interdisciplinar.

\section{INTRODUÇÃO}

$\mathrm{O}$ presente trabalho tem por finalidade abordar a questão da autonomia, enquanto princípio fundamental da Bioética, sob um enfoque interdisciplinar, tal qual se caracteriza a própria disciplina.

A idéia defendida no trabalho e tomada como ponto de partida é a seguinte afirmativa: "o ser humano não nasce autônomo, torna-se autônomo, e para isto contribuem variáveis estruturais biológicas, psíquicas e socioculturais"1.

Pretende-se demonstrar que no seu processo de desenvolvimento biológico, psicológico e social, o ser humano é influenciado por diversas variáveis, que irão, de certa forma, determinar o "grau" de autonomia que ele possui.

Essas variáveis não contaminam a sua autonomia, ao contrário, fazem parte dela. Mas, existem fatores sócio-econômicos e culturais, igualmente externos, que influenciam o processo de escolha e tomada de decisão. Estes fatores sim reduzem a autonomia do indivíduo.

Somente através de uma abordagem interdisciplinar é que se pode compreender a gama de variáveis que se inter-relacionam e se complementam de modo a constituir a noção de autonomia do ser humano.

\section{Interdisciplinaridade e bioética}

Observa-se que com a evolução da sociedade e das complexas relações que dela exsurgem, cada vez mais uma ciência necessita buscar conhecimentos e conceitos de outras ciências para melhor estudar o seu campo de atuação. Daí surge a noção de interdisciplinaridade, que pode ser conceituada como "a transferência de métodos de uma disciplina para outra"2.

Garrafa et al. ${ }^{2}$ salientam a importância da distinção entre interdisciplinaridade e multidisciplinaridade, categorias comumente referidas como sinônimos, mas que são distintas. Esta última, também denominada de pluridisciplinaridade, diz respeito ao "estudo de um objeto de uma mesma e única disciplina por várias ciências ao mesmo tempo". Nesse sentido, o enfoque multidisciplinar ultrapassa a disciplina, "mas seu resultado continua limitado à estrutura do estudo disciplinar".

De acordo com Nicolescu ${ }^{3}$, existem três graus de interdisciplinaridade: "grau de aplicação", no qual se aplica um método próprio de uma disciplina a outra; "grau epistemológico", no qual o método de uma disciplina influencia a epistemologia de outra disciplina; e "grau de geração de disciplinas", no qual vários conhecimentos de disciplinas diversas se juntam para criar outra disciplina, não havendo exemplo melhor que a Bioética.

A palavra Bioética foi utilizada pela primeira vez em 1970 por Van Rensselaer Potter, doutor em bioquímica e pesquisador na área de oncologia da Universidade de Wisconsin, EUA, em artigo científico que resumia um capítulo do livro que estava em vias de ser publicado - Bioethics, bridge to the future $(1971)^{9}$.

Em 1978, Warren Reich, do Kennedy Institute of Ethics, Universidade de Georgetown, EUA, organizou a primeira versão da Enciclopédia de Bioética, que trazia a seguinte definição da disciplina: "estudo sistemático da conduta humana na área das ciências da vida e a atenção à saúde, enquanto que esta conduta é examinada à luz dos princípios e valores morais"4.

David Roy, em 1979, conceituava Bioética como o "estudo interdisciplinar do conjunto das condições exigidas para uma administração responsável da vida humana, ou da pessoa humana, tendo em vista os progressos rápidos e complexos do saber e das tecnologias biomédicas"5.

Em 1995, em nova edição da Enciclopédia de Bioética, Reich aperfeiçoou sua definição anterior de Bioética, conceituando-a como "estudo sistemático das dimensões morais - incluindo visão moral, decisões, conduta e políticas - das ciências da vida e atenção à saúde, utilizando uma variedade de metodologias éticas em um cenário interdisciplinar"5.

A questão da interdisciplinaridade torna-se interessante, pois, se num primeiro momento histórico as ciências lutavam por independência no desejo de firmar sua autonomia, seu objeto e campo de atuação, dissociando-se, sobretudo, da Filosofia, conquistado tudo isso elas se voltam umas às outras novamente. Percebeu-se que na busca incessante pelo conhecimento e aprimoramento científico, as ciências "autônomas" não possuem tanta autonomia assim e necessitam uma das outras para conseguir abarcar uma visão mais completa e aprimorada de seu objeto de estudo.

Morin destaca esse processo com certo pessimismo ao afirmar que "foi por meio da especialização que a humanidade experimentou o desenvolvimento dos conhecimentos; no entanto, o preço pago para se atingir este estágio revelou-se muito alto"6.

O alto preço ao qual Morin se refere é a compartimentação do saber, que não raro dificulta ou até mesmo inviabiliza a compreensão do todo 6 . "A fragmentação do conhecimento em disciplinas afasta o sujeito de seu objeto, além de acabar tão especializadas que se tornam incapazes de dialogar 
Sá LV. Oliveira RA de. Autonomia: uma abordagem interdisciplinar.

entre si. Todo esse distanciamento impede o desenvolvimento do processo de humanização entre diferentes disciplinas, tornando-as impessoais e desvinculadas de qualquer contexto cultural e social"2.

A Bioética, no entanto, já nasce interdisciplinar. Daí a dificuldade epistemológica de se fortalecer como ciência, notadamente diante da herança de três séculos de fragmentação do saber com a criação e desenvolvimento das ciências modernas. Ela surge justamente como uma tentativa de aproximar as ciências biomédicas da ética, diante do alto grau de desenvolvimento científico alcançado, o qual as ciências humanas não lograram acompanhar. "A bioética surge nesse contexto de crise do poder médico e científico, em que a ética médica não é suficiente para responder à democratização dos saberes, ao pluralismo dos valores e à secularização da sociedade" .

O enfoque da Bioética evoluiu de modo a abarcar uma gama cada vez maior e diversificada de campos do saber. Se num primeiro momento o foco da Bioética era a ética aplicada à medicina, à assistência médica e às questões de saúde, atualmente ela abarca uma série de disciplinas, tanto da área da medicina e da saúde (odontologia, enfermagem, medicina veterinária, farmácia, engenharia genética) quanto da área humana (filosofia, sociologia, psicologia, direito), que podem ser simplesmente agrupadas sob o rótulo de "ciências da vida".

Daí a definição mais singela que se pode atribuir à Bioética: "ética da vida".

Stephen Toulmin, no texto "How medicine saved the life of ethics", de 1982, aponta para o fato de como problemas de tomada de decisões que surgiram no âmbito das ciências médicas levaram à retomada de discussões éticas, resgatando o estudo desta ciência.

Mas a Bioética é certamente mais que o "renascimento da ética". É uma "nova ética capaz de garantir a sobrevivência da humanidade mediante um estreito diálogo entre as ciências biomédicas e as ciências humanas"9, no qual se utilizam várias ferramentas disciplinares para tentar compreender e resolver os conflitos morais que surgem das ações humanas sobre qualquer sistema e processo vivo, nas sociedades contemporâneas complexas ${ }^{10}$.

A Bioética não se utiliza simplesmente dos conhecimentos de outras ciências, mas cria um espaço de diálogo interdisciplinar, ou seja, de colaboração e interação de diferentes áreas de conhecimento ${ }^{5}$.

Cook et al. ${ }^{11}$ apontam para uma distinção do sentido estrito e do sentido amplo que a Bioética pode assumir. No primeiro caso, a Bioética "é uma subdivisão do corpo da ética que se aplica às relações entre profissionais de saúde e os receptores de seus cuidados." Já em sentido amplo, a bioética é tida como "um campo multidisciplinar de pesquisa/indagação, tanto acadêmico como profissional, que trata de questões éticas na prática clínica e na atenção à saúde, nas pesquisas biomédicas envolvendo seres humanos e animais, nas políticas públicas de saúde e no meio ambiente".

Muñoz e Fortes ${ }^{1}$ fazem interessante paralelo entre a contribuição da Revolução Francesa para a evolução das relações sociais e a "Revolução Bioética" para a evolução da relação médico-paciente: "A Revolução Francesa estabeleceu três princípios básicos para a existência de uma sociedade humana justa, onde os homens possam viver com dignidade: liberdade, igualdade e fraternidade. Em bioética, a relação médico-paciente pode reduzir-se a três tipos de agentes: o médico, o paciente e a sociedade. Cada um com um significado moral específico: o paciente atua guiado pelo princípio da autonomia, o médico pelo da beneficência e a sociedade pelo da justiça. $A$ autonomia corresponde, nesse sentido, ao princípio da liberdade, a beneficência ao da fraternidade e a justiça ao de igualdade"1.

Feitas estas considerações iniciais, cumpre estabelecer que a corrente ideológica da Bioética que se tem por base no presente trabalho é o principialismo, de Tom Beauchamp e James Childress, tentativa mais antiga de teorização em Bioética e até hoje muito útil como diretriz a guiar o processo de tomada de decisões em conflitos e problemas bioéticos.

O referencial teórico proposto por Beauchamp e Childress em "Principles of Biomedical Ethics", de 1979, constitui-se na escola bioética baseada no uso dos princípios como modelo explicativo. Em síntese, o principialismo estabelece quatro princípios teóricos. São eles: autonomia, não-maleficência, beneficência e justiça. Na prática, o principialismo concebe seu método como uma aplicação destes princípios a casos concretos, aos dilemas éticos. Este modelo objetiva oferecer um quadro formal, mas útil a todos, no sentido de que cada um possa por eles guiar-se e encontrar soluções próprias a problemas diversos ${ }^{12}$.

Em linhas gerais, o princípio da autonomia "exprime a capacidade, para o indivíduo, de decidir por ele mesmo, o que implica que ele seja racionalmente informado e que influências externas não determinem sua ação"?.

O princípio da não-maleficência, encontrado no Juramento Hipocrático, preceitua "não causar dano". Isto quer dizer que se o profissional de saúde não 
Sá LV. Oliveira RA de. Autonomia: uma abordagem interdisciplinar.

pode fazer um bem ao paciente, deve então, ao menos, evitar causar-lhe um mal.

O princípio da beneficência, por sua vez, considerado como um dos preceitos básicos da ética pode ser enunciado da seguinte forma: fazer o bem aos outros; agir em benefício dos outros. Agnol ${ }^{4}$ aponta para a distinção da beneficência geral da beneficência específica. "A beneficência geral é direcionada para todas as pessoas, indistinta e imparcialmente, enquanto a específica está relacionada com as pessoas com as quais se mantém relações especiais"4.

Nesse sentido, para os profissionais de saúde, está-se diante da beneficência específica, na medida em que possuem uma relação especial com o paciente. "O profissional da saúde tem o dever, estabelecido a partir do Juramento Hipocrático, de agir em benefício do paciente. Ele não faz caridade, cumpre o dever de beneficência"4.

Por fim, o princípio da justiça remete à noção de igualdade: a raça, a classe social, a nacionalidade não podem ser utilizados como critérios de distinção para a alocação de recursos, distribuição de bens, oferecimento de oportunidades ou para escolha de tratamento médico. Deve-se dar a todos a mesma oportunidade de acesso à saúde. Segundo Beauchamp e Childress ${ }^{12}$, o princípio da justiça é a expressão da justiça distributiva. Justiça distributiva, por sua vez, é a distribuição justa, eqüitativa e apropriada na sociedade, de acordo com normas que estruturam os termos da cooperação social.

Segundo Cook et al. ${ }^{11}$, "o uso de princípios da bioética é, freqüentemente, empregado por críticos para censurar o uso mecânico ou a priorização de um grupo limitado de princípios bioéticos observados, que parecem ser compartilhados por vários adeptos de diferentes correntes bioéticas." Apesar das críticas ao principialismo, imperioso reconhecer que "um número limitado de princípios fundamentais oferece coerência e racionalidade às discussões éticas, e permite comparações e contradições sobre um ponto comum"11

Importante consignar que estes princípios não obedecem a qualquer disposição hierárquica e são válidos prima facie. Vale dizer que não são absolutos e, em caso de conflito entre esses princípios, a prevalência de um em detrimento de outro deverá ser determinada pelas circunstâncias do caso concreto. Aliás, Cook et al. ${ }^{11}$ apontam para o fato de que "muito da controvérsia bioética envolve as discussões sobre qual deles deve ser priorizado para resolver problemas específicos".

Estabelecidas tais premissas, passemos, então, à análise do princípio da autonomia através de uma abordagem interdisciplinar, vale dizer, como os fatores biológicos, psicológicos e sociais do desenvolvimento do indivíduo influenciam na formação de sua autonomia. Correlacionam-se os diferentes campos do saber que compõem o terreno fértil para as discussões bioéticas.

\section{AUTONOMIA}

Gramaticalmente, a palavra autonomia significa "faculdade de se governar por si mesmo"13.

Obviamente que este vocábulo, em seu significado mais sucinto e objetivo possível, pode ser aplicado a qualquer instituto ou instituição. Mas no presente ensaio, tratar-se-á, sobremaneira, da aplicação do vocábulo para designar uma característica ou qualidade do ser humano.

Embora seja praticamente um consenso que a autonomia é um direito inerente à espécie humana; um direito intimamente relacionado com a liberdade; um direito natural, fundamental, constitucional; o ser humano não nasce autônomo, na medida em que não pode governar-se por si mesmo quando nasce, ou desde o nascimento. Aliás, uma característica da espécie humana é justamente a (longa) dependência dos descendentes aos ascendentes. Vale dizer que não há como um bebê sobreviver se não houver alguém que lhe dê alimento, que Ihe higienize, que Ihe aqueça.

Ao nascer, o ser humano não possui qualquer autonomia, pois não pode, de modo algum, governarse por si próprio. Ele está totalmente vinculado às forças biológicas (fome, frio, sede, calor) e reflexos inatos (chorar quando tem fome, soluçar, mexer os membros superiores e inferiores involuntariamente, espirrar, bocejar).

Dessa forma, o ser humano torna-se autônomo. E neste caminho de desenvolvimento e conseqüente conquista de sua autonomia, o indivíduo é influenciado por diversas variáveis, que irão justamente determinar o "grau" de autonomia que ele terá ou poderá alcançar.

Em breve digressão histórica, o termo autonomia possui origem grega e remete à idéia de auto-governo. Foi empregado no seio da democracia grega para indicar as formas de governo (a polis) ${ }^{14}$.

Ou seja, a noção de autonomia estava circunscrita à forma de governo. Ter autonomia era poder governar a sociedade (que era composta apenas dos cidadãos, conforme concebidos à época, excluídos, por exemplo, escravos e mulheres) segundo as leis de regência. Para Aristóteles, "o etos (ETOS. [Do gr. éthos, 'costume', 'uso', 'característica'.] Modo de ser, temperamento ou disposição interior, de natureza emocional ou moral; O espírito que anima uma 
coletividade, instituição, etc; (Sociol. Antrop.) Aquilo que é característico e predominante nas atitudes e sentimentos dos indivíduos de um povo, grupo ou comunidade, e que marca suas realizações ou manifestações culturais. Dicionário Aurélio ${ }^{15}$. Século XXI. Versão digital 3.0. Nota não existente no original.) do indivíduo permanecia referido e adstrito à polis dos cidadãos"15.

Dando um salto na história até a Era Medieval, na qual a religião exerceu fortíssima influência e desempenhou papel preponderante no pensamento filosófico, tem-se que "a moral cristã concebia a autonomia como subordinação a Deus"16.

Vale dizer, pressupunha a livre aceitação, por parte do indivíduo, de sua condição de origem divina - o ser humano concebido como obra de Deus -, bem como a aceitação dos desígnios de Deus. A vontade humana, fosse individual ou coletiva, estava adstrita à vontade de Deus. Vontade essa que, na prática, representava a vontade das autoridades monárquicas, dos chefes de família ou das próprias forças da natureza.

Foi a partir da Modernidade, isto é, do movimento cultural e social iniciado pela Renascença, que a idéia de indivíduo incorporou-se ao cenário da reflexão filosófica e política. A Modernidade se caracteriza pela hegemonia da razão e isto repercute nas teorias éticas. "A autonomia passa a ser concebida como autonomia da razão"16.

O conceito de autonomia passa, então, a aplicarse ao indivíduo, enquanto ser dotado de razão, definindo-se como autônomo o indivíduo que "age livremente de acordo com um plano escolhido por ele mesmo, da mesma forma que um governo independente administra seu território e define suas políticas"17.

Esta noção se coaduna com o conceito ético do termo, segundo o qual autonomia significa a "condição pela qual o homem pretende poder escolher as leis que regem sua conduta"13.

Nesse contexto, a pessoa é predominantemente tomada como ser racional dotado de vontade própria e realizando-se no exercício da sua liberdade ${ }^{18}$.

"Autonomia é capacidade para deliberar, isto é, calcular os meios necessários para atingir um fim, e para escolher". Em outros termos, é autônomo um ser "capaz de agir livremente"4; "capaz de deliberar sobre seus objetivos pessoais e de agir na direção desta deliberação"19.

Percebe-se, pois, que autonomia pressupõe razão; pressupõe vontade; pressupõe um comportamento (positivo ou negativo) como resultado de uma escolha, diante de uma situação que se lhe é posta e pressupõe liberdade para escolher.

A razão, enquanto "faculdade que tem o ser humano de avaliar, julgar, ponderar idéias"13 embora característica intrínseca à espécie humana, deve ser desenvolvida para poder ser exercida. Daí a importância do estímulo ao raciocínio, através de exercícios mentais, por exemplo, ao longo do desenvolvimento da criança. Todos possuem razão, mas nem todos são capazes de exercê-la. Aqueles que receberam maiores estímulos ao longo de seu desenvolvimento possuirão maior capacidade de raciocinar.

A vontade, por sua vez, constitui-se na "faculdade de representar mentalmente um ato que pode ou não ser praticado em obediência a um impulso ou a motivos ditados pela razão" 13 .

Praticar ou não um ato, seja em obediência a impulsos, seja em obediência à razão, consubstancia escolha.

Vontade e razão decorrem do desenvolvimento do indivíduo, processo bio-psico-social que se inicia na vida intra-uterina e só termina com a morte. Podese falar, assim, em desenvolvimento biológico, emocional, intelectual e social do ser humano.

Cumpre observar que "o desenvolvimento biológico não é independente do social e este não está separado do intelectual. Em suma, todos estão relacionados. O ser humano é uma unidade e nada acontece isoladamente"20.

Sucintamente, o desenvolvimento depende de dois fatores básicos: a maturação e o ambiente. "Maturação é um processo biológico, é o aspecto inato do desenvolvimento. Maturação se refere ao crescimento de células, tecidos, músculos e órgãos." Já o ambiente engloba "todas as experiências vividas pela criança e oriundas do meio circundante: a educação, a influência dos pais, a alimentação, as doenças"20.

O desenvolvimento compreende, portanto, uma faceta biológica e outra social.

O comportamento, por sua vez, é o "produto do funcionamento de três mecanismos fisiológicos, a cada qual corresponde uma estrutura orgânica básica. São eles: o mecanismo receptor, constituído pelos órgãos dos sentidos e que têm como função captar os estímulos do meio; o mecanismo efetor, que compreende os músculos e as glândulas e reage aos estímulos captados; e o mecanismo conector, constituído pelo sistema nervoso que estabelece a conexão entre receptor e efetor"20.

O processo pelo qual o organismo capta e conduz estímulos é sucintamente explicado pela psicologia fisiológica, ciência que estuda o modo pelo qual as 
Sá LV. Oliveira RA de. Autonomia: uma abordagem interdisciplinar.

mudanças no interior do organismo levam a alterações no comportamento. Destaca-se:

As células receptoras estão ligadas a fibras de células nervosas. Quando uma célula receptora é estimulada, a energia estimuladora é transduzida (transdução é o nome do processo de transformação de um tipo de energia em outro) em energia elétrica nervosa. Se a energia for suficientemente grande, originará um impulso nervoso que é transmitido, através de várias células nervosas, ao córtex cerebral ou a outra região do sistema nervoso central. Esta descrição simplificada do processo de recepção de estímulos mostra que o tipo de experiência sensorial que temos depende do receptor estimulado e não do tipo de estimulação. Por isso é possível afirmar que não temos uma experiência direta do mundo, mas que a nossa experiência sensorial é decorrente da estimulação, no córtex, de uma área sensorial especializada, ponto de "chegada" de uma via sensorial específica. Os órgãos dos sentidos, por sua vez, mesmo em perfeitas condições, também não captam todos os estímulos existentes ao redor do organismo. Existem limiares, isto é, pontos abaixo dos quais não há sensação. Em outras palavras, a energia precisa estar acima de certo nível de intensidade para que provoque um efeito sensorial ${ }^{20}$.

Dessa forma, tem-se que a percepção sensorial de um mesmo fato social ou de determinada circunstância física pode ser concebida de diversas formas por um ou outro indivíduo, na medida em que a constituição física de seus mecanismos de percepção e transporte de estímulos pode não ser a mesma.

Além disso, o meio ambiente, fator externo ao indivíduo, desempenha papel preponderante no seu desenvolvimento. Ele integra esse processo. Isto explicaria, por exemplo, por que irmãos gêmeos univitelinos, de constituição biológica quase que idêntica, mas criados em ambientes distintos, podem interagir com o meio e ter comportamentos completamente diferentes. Não se trata apenas de uma questão de "personalidade", mas sim como os fatores internos e externos ao indivíduo contribuem para formar essa personalidade.

A estrutura da personalidade, "concebida originalmente em termos topográficos como consciente, pré-consciente e inconsciente," é substituída, na teoria freudiana, pelo "conceito dinâmico do id, que representa as forças biológicas, instintivas da personalidade, o ego, que representa o princípio da realidade, e o superego, que representa as forças repressivas da sociedade"21.

O id e o superego representam as influências do passado: o primeiro, a influência da hereditariedade; o segundo, a influência essencialmente do que é retirado de outras pessoas. Já o ego é principalmente determinado pela própria experiência do indivíduo. Interessante notar que o id, o ego e o superego não são entidades isoladas na personalidade humana. É justamente a interação dinâmica desses três elementos que constitui a personalidade do homem ${ }^{21}$.

Jean Piaget ${ }^{21}$ (1896-1980) - referência da psicologia evolutiva contemporânea, embora não fosse psicólogo de formação - defendeu a necessidade de uma psicologia fundamentada na biologia e voltada para problemas epistemológicos. Trabalhou com a possibilidade de, na busca pelo conhecimento, encontrar um método científico que pudesse servir de elo entre o método filosófico, muito especulativo, e o método científico propriamente dito, o qual era, segundo ele, demasiadamente objetivo e preocupado apenas com o fato em si.

Piaget ${ }^{21}$ procurou encontrar um meio de integrar a biologia e a epistemologia, partindo do estudo da psicologia como possível solução para esse problema.

Nesse sentido, a psicologia seria uma ponte entre a biologia e a epistemologia, tal qual a bioética o é, segundo Potter ${ }^{9}$, entre as ciências biomédicas e a ética.

Segundo Piaget, "não se pode compreender o produto final sem se conhecer o seu processo evolutivo" ${ }^{\prime 2}$.

Esse pensamento se encaixa perfeitamente na noção de que a autonomia, considerada como produto final, somente pode ser compreendida na medida em que se conhece o seu processo evolutivo, vale dizer, o processo de como a autonomia se estrutura ao longo do desenvolvimento bio-psico-social do indivíduo.

Erik Erikson (1902-1994), também estudioso da psicologia evolutiva, destacou os aspectos culturais do processo evolutivo da personalidade. Segundo o autor, "os indivíduos enfrentam diferentes tarefas sócio psicológicas à medida que crescem ${ }^{20}$. Novas exigências vão sendo feitas pela sociedade e novas formas de agir devem ser desenvolvidas. A forma como cada um vai resolver os desafios de cada um dos estágios vai determinar sua personalidade, sua identidade, enfim seu ajustamento"20.

Erikson destaca oito estágios no processo evolutivo da personalidade, cada um deles apresenta duas alternativas: "quando o estágio evolutivo é satisfatoriamente alcançado, o produto será uma personalidade saudável; quando não é atingido, o resultado será uma personalidade emocionalmente imatura ou desajustada"21.

Para ele, o senso de autonomia é adquirido na 
Sá LV. Oliveira RA de. Autonomia: uma abordagem interdisciplinar.

infância, no estágio evolutivo que convencionou chamar de "segunda idade", que vai de 1 a 3 anos de idade.

"[...] Nessa idade a criança já caminha, corre, puxa, empurra, enfim, vive em movimento. Respeitados os limites da segurança, os pais podem deixar que a criança se movimente, aja, se envolva no maior número de atividade possíveis. Se isso ocorrer, a criança desenvolverá o senso de autonomia. Se, porém os pais forem muito exigentes na disciplina, repreenderem e castigarem a criança, ela crescerá com vergonha e dúvida"20.

As considerações de Erikson são relevantes para o desenvolvimento da autonomia do indivíduo, pois constata que a atitude dos pais, em tão tenra idade da criança, é fundamental para a aquisição do senso de autonomia na personalidade do ser humano. Essa constatação se coaduna com a noção de que o ambiente desempenha papel fundamental no desenvolvimento do indivíduo.

Pode-se afirmar que, nessa fase do desenvolvimento individual, a noção de autonomia não estaria relacionada a um processo de tomada de decisão, mas a um senso de liberdade de movimentos, interação com o meio ambiente e experimentações de novas sensações.

Ainda segundo Erikson ${ }^{20}$, ao vencer as crises que se lhe são postas em cada estágio evolutivo, da qual se destacou apenas o estágio relativo ao desenvolvimento do senso de autonomia, o indivíduo "desenvolve o senso de identidade pessoal e se torna confiante, seguro em suas emoções, adquire controle sobre seus impulsos, relaciona-se bem com outros." Já aqueles que não conseguem superar as crises desenvolvem "identidades confusas, isto é, tem crise de identidade, são alienados da sociedade, duvidam de suas próprias capacidades, não tem auto confiança e não sabem realmente o que querem.".

Saber exatamente quem se é e o que se quer, segundo Habermas ${ }^{15}$, filósofo e sociólogo alemão, é um pressuposto fundamental para o processo de escolha. Afirma o autor que "aquilo que se deve fazer de uma maneira racional é determinado, em parte, por aquilo que se quer: trata-se de uma escolha racional dos meios a partir das metas dadas ou de uma ponderação racional das metas a partir das preferências existentes" 15 .

A exata compreensão de si auxilia no processo de escolhas e tomada de decisões. Nas palavras de Habermas ${ }^{15}$, "o asseguramento clínico da própria identidade requer um compreender apropriador: a apropriação da história da própria vida como também das tradições e dos contextos de vida que determinaram o processo de formação próprio. [...] Será possível decidir com melhores fundamentos [...] depois que se tenha tornado claro quem se é e quem se gostaria de ser"15.

Embora alheio às considerações de psicologia evolutiva, o filósofo inglês John Stuart Mill (1806-1873) sabidamente congregou a essência biológica e psicológica do ser humano ao propor que "sobre si mesmo, sobre seu corpo e sua mente, o indivíduo é soberano"19.

Mas faltou-lhe um componente que é sobremaneira fundamental na formação da personalidade do indivíduo e que irá influenciar a noção que se tem de autonomia: o componente social, que integra o desenvolvimento do indivíduo, ao qual Habermas ${ }^{15}$ se referiu como identidade coletiva.

O autor destaca que a identidade individual é marcada pelas identidades coletivas e a história de vida do indivíduo está inserida em um contexto de histórias de vida que se entremeiam ${ }^{15}$.

Esta noção da influência do meio ambiente, enquanto fator externo, no processo de formação individual e, conseqüentemente, no processo de tomada de decisão, não só abarca o processo de desenvolvimento individual (maturação + ambiente, conforme já mencionado), como vai além.

A afirmativa de Habermas ${ }^{15}$ acerca da identidade coletiva nos remete à Sociologia, enquanto ciência que estuda as "relações que surgem e se reproduzem, especificamente, com base na coexistência de diferentes pessoas ou grupos em uma sociedade mais ampla, bem como das instituições, normas, leis e valores conscientes ou inconscientes que essas relações tendem a gerar no seio do grupo"13.

Isto quer dizer que, ainda que o indivíduo tenha se desenvolvido biológica e psicologicamente com perfeição, no processo de tomada de decisão, na escolha entre um comportamento ou outro, ele levará em consideração os valores e as verdades que tem de si e em si, mas também as do grupo, que pode ser a família, a escola, a turma de amigos, o condomínio, o bairro, a cidade, o país, ou ainda todos eles conjugados.

Goldim" ${ }^{19}$ afirma que "a noção de autonomia alcançou uma formulação moral sistemática com a Fundamentação da Metafísica dos Costumes (1785), de Immanuel Kant (1724-1804)" que propôs o imperativo categórico, segundo o qual uma máxima é justa apenas se todos podem querer que ela seja seguida por cada um em situações comparáveis. De acordo com esta proposta a autonomia não seria incondicional, mas passaria por um critério de universalidade ${ }^{19}$. 
Sá LV. Oliveira RA de. Autonomia: uma abordagem interdisciplinar.

Para Kant, a autonomia era absoluta: nenhum motivo de qualquer ordem poderia interferir na decisão do indivíduo, sob pena de contaminar-lhe a vontade com elementos que a tornariam dependente de outra coisa que não ela mesma ${ }^{16}$.

O critério de universalidade proposto por Kant deve ser interpretado, fazendo-se dele uma espécie de releitura, nomeada de "perspectiva social" da autonomia. Assim, a autonomia absoluta, como na perspectiva de Kant, não existe, na medida em que, como já visto, há condicionantes biológicos e psicológicos que influenciam a própria noção de autonomia do indivíduo.

Dessa maneira, inversamente à noção de autonomia enunciada por Kant, há diferentes motivos de diversas ordens que interferem na decisão do indivíduo. Não obstante, isto não Ihe contamina a vontade, que é dependente de outras coisas e não existe por si mesma. Esses diferentes motivos de diversas ordens fazem parte do processo de escolha, do exercício da liberdade, que consubstanciam a noção de autonomia alhures destacada. "Ainda que a vontade esteja mais ou menos determinada por múltiplos fatores, ela se exerce, e o sujeito projetase diante de si mesmo de certa maneira, a qual depende das escolhas que faz"16.

Ora, levando-se em conta o próprio conceito gramatical da palavra, já expresso, a vontade é objeto da razão. Esta, por sua vez, pressupõe deliberação, ponderação, raciocínio. E para fazer isto o indivíduo não se isola e se tranca em um mundo só seu, alheio à realidade em que vive. Ao contrário, muitas vezes o processo de raciocínio é compartilhado com o grupo. Ouvir a opinião de outras pessoas; conversar com os mais velhos; consultar especialistas; buscar por relatos de pessoas mais experientes que já passaram por determinada situação; tudo isso não apenas influi como faz parte do processo escolha. Fazer tudo isso é exercitar autonomia.

Muñoz e Fortes ${ }^{1}$ acertadamente destacam que para existir "uma ação autônoma é também" necessária a existência de alternativas de ação ou que seja possível que o agente as crie, pois se existe apenas um único caminho a ser seguido, uma única forma de algo ser realizado, não há propriamente o exercício da autonomia.

Nesse diapasão, os autores destacam que "os grupos sócio e economicamente vulneráveis, os mais desprovidos de recursos, têm menos alternativas de escolha em suas vidas, o que afeta o desenvolvimento de seu potencial de ampla autonomia"1.

Essa consideração encontra respaldo no pensamento de Max Charlesworth, filósofo australiano e professor emérito na Universidade de Deakin, Austrália, que afirma que ninguém está capacitado para desenvolver a liberdade pessoal e se sentir autônomo se está angustiado por situações externas que influem na sua tomada de decisão. São exemplos: a pobreza, a privação de educação básica ou a falta de acesso à ordem pública. Charlesworth ${ }^{22}$ sustenta ainda que a assistência à saúde básica também seja uma condição para o exercício da autonomia.

Percebe-se aqui que os fatores sócio-econômicos e culturais destacados por Munhoz e Fortes ${ }^{1}$, bem como por Charlesworth ${ }^{22}$ dissociam-se dos fatores sociais que integram o desenvolvimento do indivíduo (o ambiente), bem como se diferenciam dos fatores sociais que acima se denominou de "perspectiva social" da autonomia. Isto porque estes dois últimos fazerem parte do processo de escolha que integra 0 exercício da autonomia. Já os fatores sócioeconômicos e culturais reduzem ou até mesmo impedem o livre exercício da autonomia, na medida em que diminuem as possibilidades de escolha por parte do indivíduo. E, conforme mencionado, autonomia pressupõe liberdade de escolha.

Jean Piaget, ao afirmar que autonomia é a "capacidade de coordenação de diferentes perspectivas sociais com o pressuposto do respeito recíproco", insere ao referido conceito a noção de respeito, respeito à autonomia ${ }^{19}$.

Respeitar a autonomia é "dar peso às opiniões e às escolhas das pessoas autônomas e, ao mesmo tempo, evitar obstruir suas ações a não ser que prejudiquem os outros"4.

"Respeitar a autonomia é reconhecer que ao indivíduo cabe possuir certos pontos de vista e que é ele quem deve deliberar e tomar decisões segundo seu próprio plano de vida e ação embasado em crenças, aspirações e valores próprios"1.

Vale dizer que se devem tolerar as crenças nãousuais e as escolhas pessoais dos indivíduos, até porque, oportuno lembrar, "o corpo, a dor, o sofrimento, a doença são da própria pessoa"1.

Não se costuma questionar a decisão de uma pessoa quando se está de acordo com ela. Ou seja, comumente, somente quando a decisão do indivíduo conflita com a da família, do grupo, ou com aquela majoritariamente aceita pela própria sociedade é que a validade da decisão é questionada ${ }^{1}$.

Muñoz e Fortes ${ }^{1}$ bem destacam essa questão ao afirmar que "a garantia do respeito à autonomia requer o respeito a padrões morais que não sejam convencionais, padrões que não são majoritários na sociedade". 
Sá LV. Oliveira RA de. Autonomia: uma abordagem interdisciplinar.

E concluem sabiamente: "respeitar a autonomia pressupõe a aceitação do pluralismo ético-social, característico de nosso tempo"'.

Em bioética, o princípio da autonomia evoluiu de modo a abarcar a noção de respeito à pessoa. Segundo este princípio a autonomia incorpora duas convicções éticas: "os indivíduos devem ser tratados como agentes autônomos" e "as pessoas com autonomia diminuída devem ser protegidas"19.

Assim, o princípio do respeito às pessoas divide-se em dois pressupostos: o de reconhecer a autonomia e o de proteger aqueles que possuem autonomia reduzida.

Tendo em vista todas as considerações feitas alhures acerca do princípio do respeito à autonomia, a questão que se coloca é quando saber se o indivíduo age de maneira autônoma ou se, por qualquer circunstância, está com essa capacidade reduzida ou se está, ainda que momentaneamente, agindo de maneira não autônoma. Ou seja, qual seria o liame entre o respeito à autonomia e a proteção àqueles que a tem reduzida?

A avaliação da livre manifestação decisória de um paciente é uma das mais complexas questões éticas impostas aos profissionais de saúde ${ }^{1}$.

Essa constatação, no entanto, no âmbito da medicina, com exceção dos casos óbvios de perda da autonomia (estado de coma, por exemplo), deve ser tomada pelo médico em conjunto com os familiares do paciente. Seria uma espécie de convicção pessoal fundamentada em uma decisão de equipe.

Já no âmbito legal, presume-se que um adulto é autônomo até que o Estado, através do Poder Judiciário, o considere incapaz de se autodeterminar e limite seus direitos civis. É a chamada interdição. Há também aqueles que são legalmente tutelados pelo Estado, como os menores (Estatuto da Criança e do Adolescente) e os idosos (Estatuto do Idoso). Nesses casos, as normas protetivas devem ser observadas.

\section{CONCLUSÃO}

O ser humano não nasce autônomo, mas tornase autônomo, através de um processo de desenvolvimento bio-psico-social. Daí a necessidade de se analisar a autonomia sob o enfoque das ciências sociais, de modo a congregar conceitos e possibilitar a compreensão do todo. Na medida em que o desenvolvimento bio-psico-social do homem não acontece isoladamente, o estudo dessas variáveis que compõem o ser deve ser feito igualmente de forma integrada.
A autonomia, concebida como a possibilidade do indivíduo escolher as regras que regem sua conduta, pressupõe uma atividade racional do indivíduo, de modo a determinar-se conforme um comportamento estabelecido através de um processo de escolha. Para tanto, o exercício da autonomia pressupõe liberdade de escolha, pressupõe alternativas de escolha.

A liberdade que é pressuposto da autonomia, não é uma liberdade incondicional, livre de coações internas ou externas. Ao contrário, ela é influenciada pela constituição biológica, psicológica e social do indivíduo. Dessa forma, aquela noção de que o exercício da autonomia pressupõe tomada de decisões alheias a qualquer fator externo é um engano. A razão é característica precípua da espécie humana, no entanto, o seu livre exercício pressupõe desenvolvimento biológico, mental e social apropriado.

A noção de autonomia assume diferentes perspectivas, desde as mais individualistas até as que inserem o indivíduo no grupo social. Sustentouse no presente trabalho que a relação do indivíduo com o grupo social e a influência que este exerce naquele, faz parte do seu processo de formação e, por isso mesmo, integra a gama de variáveis que se inter-relacionam para formar a autonomia. Vale dizer que, apesar dos condicionantes biológicos, psicológicos e sociais, o ser humano pode se agir dentro de uma margem própria de ação e deliberação. Isto é autonomia.

Já a influência, igualmente externa, de fatores sócio-econômicos e culturais, estes sim interferem na autonomia individual, na medida em que diminuem as possibilidades de escolhas. Reduzem ou até mesmo inviabilizam a margem própria de ação e deliberação.

Muñoz e Fortes questionam se "num mundo governado pela razão liberada das amarras que a prendiam em épocas passadas, o homem pode viver efetivamente de maneira emancipada, isto é, realizar a autonomia enquanto condição da vida ética"'.

Essa emancipação é relativa, na medida em que condicionada por diversos fatores internos e externos ao indivíduo, mas ainda assim existe. O seu desenvolvimento biológico e psicológico, bem como a sua interação com a sociedade, desde a infância, Ihe dão condicionantes morais e comportamentais que integram o processo de desenvolvimento de sua autonomia individual. Em uma sociedade justa e democrática, deve-se estimular o desenvolvimento das autonomias individuais, permitindo-se escolher entre as diversas morais existentes. Deve-se, sobretudo, respeitar as diversas morais existentes em cada momento histórico e evolutivo vivido pela sociedade. 
Sá LV. Oliveira RA de. Autonomia: uma abordagem interdisciplinar.

Sá LV. Oliveira RA de. Autonomy: an interdisciplinary approach. Saúde, Ética \& Justiça. 2007;12(1/2):5-14.

ABSTRACT: Based on the supposition that man not born autonomous, but becomes autonomous through a process of bio-psycho-social development, a necessity arises to analyze autonomy with a social scientific focus, in such manner as to combine concepts and enable overall comprehension. This text proposes to demonstrate that in the process of biological, psychological and social development, mankind is influenced by diverse variables that will, in certain way, determine the "degree" of autonomy that is afforded to it. These variables do not negatively effect his autonomy, but to the contrary, taken together, are an integral pert of it. However, there are social-economic and cultural factors that influence the process of choosing and making a decision. These factors indeed reduce the autonomy of the individual.

KEY WORDS: Autonomy. Bioethics. Development.

\section{REFERÊNCIAS}

1. Muñoz DR, Fortes PAC. O princípio da autonomia e o consentimento livre e esclarecido. In: Costa SIF, Garrafa V, Oselka G, organizadores. Iniciação à bioética. Brasília, DF: Conselho Federal de Medicina; 1998. p.59.

2. Garrafa V, Kuttow M, Saada A, orrganizadores. Bases conceituais da bioética - enfoque latino-americano. Trad. Luciana Moreira Pudenzi e Nicolás Nyimi Campanário. São Paulo: Editora Gaia; 2006. p.75.

3. Nicolescu B apud Garrafa V, Kuttow M, Saada A, organizadores. Bases conceituais da bioética enfoque latino-americano. Trad. Luciana Moreira Pudenzi e Nicolás Nyimi Campanário. São Paulo: Editora Gaia; 2006. p.75.

4. Agnol DD. Bioética. Rio de Janeiro: Jorge Zahar; 2005. p.9.

5. Goldim JR. Bioética e interdisciplinaridade [acesso em 18 maio 2007]. Disponível em: http://www.ufrgs.br/ bioetica/biosubj.htm.

6. Morin E apud Garrafa V, Kuttow M, Saada Alya, organizadores. Bases conceituais da bioética enfoque latino-americano. Trad. Luciana Moreira Pudenzi e Nicolás Nyimi Campanário. São Paulo: Editora Gaia; 2006. p.79.

7. Canto-Sperber $M$, organizador. Dicionário de ética e filosofia moral. Trad. Ana Maria Ribeiro Althoff, Magda França Lopes, Maria Vitória Kessler de Sá Brito e Paulo Neves. São Leopoldo, RS: Unisinos; 2003. p.166.

8. Post SG, editor. Encyclopedia of bioethics. 3rd ed. New York: MacMillan Reference; 2004. p.279. v. 1.

9. Potter van $\mathrm{R}$ apud Faralli C. A filosofia contemporânea do direito. Trad. Candice Premaor Gullo. São Paulo: Martins Fontes; 2006. p.74.

10. Floriani CA, Schramm FR. Atendimento domiciliar ao idoso: problema ou solução? [acesso em 11 maio
2007]. Disponível em: http://www.scielosp.org/ scielo.php.

11. Cook RJ, Dickens BM, Fathalla MF. Bioética - saúde reprodutiva e direitos humanos. Rio de Janeiro: CEPIA; 2004. p.71.

12. Beauchamp TL, Childress JF apud Goldim JR. Princípio da justiça [acesso em 8 de jun. 2007]. Disponível em: http://www.ufrgs.br/bioetica/ justica.htm.

14. Batista RS, Schramm FR. A filosofia de Platão e o debate bioético sobre o fim da vida: interseções no campo da saúde pública [acesso em 11 maio 2007]. Disponível em: http://www.scielo.br/scielo.php.

15. Habermas J. Para o uso pragmático, ético e moral da razão prática. Trad. Márcio Suzuki [acesso em 17 maio de 2007]. Disponível em: http://w.w.w.scielo.br.

16. Silva FL. Da ética filosófica à ética em saúde. In: Costa SIF, Garrafa V, Oselka G, organizadores. Iniciação à bioética. Brasília, DF: Conselho Federal de Medicina; 1998. p.26.

17. Beauchamp TL, Childress JF. Princípios de ética biomédica. 4a ed. São Paulo: Edições Loyola; 2002. p.138.

18. Neves MCP. A fundamentação antropológica da bioética [acesso em 21 maio 2007]. Disponível em: http://www.portalmedico.org.br.

19. Goldim JR. Princípio do respeito à pessoa ou da autonomia [acesso em 18 maio de 2007]. Disponível em: http://www.ufrgs.br/bioetica/autonomi.htm.

20. Braghirolli EM, Bisi GP, Nicoletto U. Psicologia geral. 13a ed. Petrópolis: Vozes; 1995. p.153.

21. Rosa M. Psicologia evolutiva. Problemática do desenvolvimento. 5a ed. Petrópolis: Vozes; 1991. v.1, p.110.

22. Charlesworth M. La bioetica en una sociedad liberal. Cambridge; 1996. p.131. 